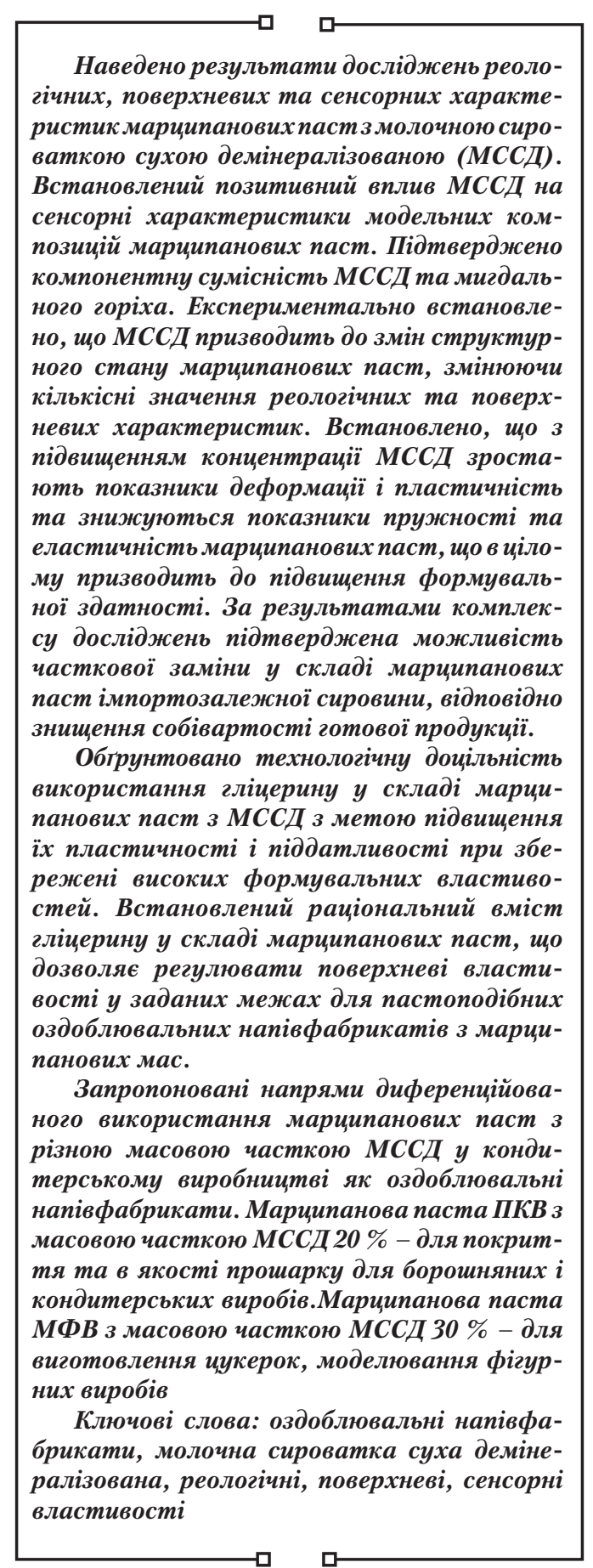

UDC 657.1 .01

DOI: $10.15587 / 1729-4061.2020 .192505$

\section{DETERMINING THE RATIONAL CONCENTRATION OF DRY DEMINERALIZED WHEY IN A FORMULATIONFOR MARZIPAN PASTES}

M. Kravchenko

Doctor of Technical Sciences, Associate Professor, Head of Department* E-mail:m.f.kravchenko@gmail.com

L. R y b c h u k

Postgraduate student*

D. Fedorova

Doctor of Technical Sciences, Associate Professor*

R. R o m a n e n ko

$\mathrm{PhD}$, Associate Professor Department of Engineering and Technical Disciplines**

V. P i d d u b n y i

Doctor of Technical Sciences, Professor Department of Mechatronics and Packaging Technology

National University of Food Technologies Volodymyrska str., 68, Kyiv, Ukraine, 03680

I. Da n y li u k

$\mathrm{PhD}$, Senior Lecturer***

K. Pala mare k $\mathrm{PhD}$, Associate Professor***

T. Marus y a k $\mathrm{PhD} * * *$

T. Nezveshchuk-Kohut $\mathrm{PhD}$, Associate Professor*** *Department of Technology and the Organization of Restaurant Business** **Kyiv National University of Trade and Economics Kyoto str., 19, Kyiv, Ukraine, 02156 ***Department of Technology and Organization of Restaurant Management Chernivtsi Institute of Trade and Economics of Kyiv National University of Trade and Economics Tsentralna sq., 7, Chernivtsi, Ukraine, 58002

\section{Introduction}

Confectionery production is one of the largest sectors of the food industry in most developed countries of the world. It is characterized by stability and low vulnerability to negative downturns in economy $[1,2]$.

Under conditions of market competition, increased attention is paid to the level of aesthetics of confectionery products. Current dressing semi-finished products for confectionery products are represented by a wide assortment of creams, fudges, chocolate pastes, marzipan, sugar, painting pastes, powders, molded ornaments from caramel, chocolate, etc. Marzipan occupies a special place among the confectionery semi-finished products due to versatility of its use in various areas of confectionery industry [3-5].

Marzipan belongs to high-calorie semi-finished products made from high-quality raw materials, for example almond nut kernel, that strongly influence demand formation and impede their widespread use in the confectionery industry. Given the high consumer preferences of marzipan pastes, 
there is a need to find new ingredients that would both reduce cost of finished products and preserve exclusivity of organoleptics and structure of marzipan pastes while improving nutrient composition. Thus, the problem of developing scientifically sound technologies of marzipan pastes with reduced content of high-value nut raw materials available for mass consumption and wide use in the confectionery industry, with predicted quality indices and improved consumption properties is urgent.

\section{Literature review and problem statement}

In the context of solving the above problem, analysis of published data and patent sources shows the possibility of partial replacement of almond flour and sugar in marzipan pastes with other formulation ingredients [6-13]. Much of these studies are devoted to exploring the possibility of replacing sugar with sweeteners and sugar substitutes but proportion of high-value nut raw materials remains unchanged rendering it impossible for marzipan pastes to be widely used in the confectionery industry. For example, the results of studies of effect of maltose syrup on changes occurring during storage of marzipan paste were presented in [6]. It has been proven that maltose syrup enhances moisture retention capacity of almond paste which prevents drying and loss of freshness and makes it possible to extend shelf life of the finished product. Technologies of marzipan pastes with low sugar content in which model compositions are presented by sodium or potassium acelsulfate and aspartame are known [7]. Disadvantage of such compositions consists in the use of synthetic sweeteners (there are studies confirming their negative impact on human health) [8,9]. A series of technologies have been developed that can significantly reduce the high caloric and glycemic properties of marzipan pastes due to the use of natural sweeteners, namely, agave syrup, erythrol, stevioside, palatinoses [10]. All these sweeteners have tens and hundreds of times higher sweetness than the sucrose sweetness but their taste profile does not fully match that of the sucrose taste profile, sweetness persists longer or disappears quickly and has a variety of flavor shades. To enhance flavor and aroma, they include a variety of unconventional raw materials such as coffee cake, chicory powder [11], pear seeds [12] and amaranth [13].

Technologies of marzipan pastes in which flour of various types are used as substitutes for almond flour, namely, flower of linseed, barley, buckwheat, corn, lentil, rice, peas [11-13]. This reduces cost of finished pastes by $25 \ldots 50 \%$, improves nutrient composition and rheological characteristics of marzipan pastes by strengthening internal adhesion forces of the marzipan paste components for better moisture retention and promotion of more homogeneous and plastic mixture structure in the forming process. However, reduced sensory characteristics are the major drawbacks of the developed marzipan pastes with these additives. Taking into account peculiarities of ingredient composition of marzipan pastes, use of the additives enriching nutrient formulation drastically changes color and taste of these products. As a result, problems arise when toning the marzipan paste to obtain an appropriate color spectrum, which makes this type of dressing semi-finished product unsuitable for topping confectionery products and shaping figured semi-finished products.

According to the results of critical review of scientific sources, it is necessary to find a comprehensive solution to a series of technological problems of creation of affordable marzipan pastes with a low content of high-value nut raw materials which would provide specified structural and mechanical properties, organoleptic characteristics and nutritional value. At the same time, it was found expedient to search for new formulation ingredients for marzipan pastes which will simultaneously provide high component compatibility while providing comprehensive solution of the set problems.

Considering factors such as economic and commodity accessibility, import substitution, nutritional and biological value, high solubility, and acceptable sensory characteristics, use of dry demineralized whey (DDW) in marzipan pastes was found expedient. DDW is obtained from curds whey by electrodialysis treatment resulting in a $90 \%$ demineralization level [14, 15]. Whey demineralization features reduction of titrated acidity, content of nitrogenous substances, organic acids, acid salts and ash. As a result, whey solubility and sweetness grow and organoleptic properties improve [16, 17]. DDW has a sweet taste without extraneous flavors and odors which significantly expands scope of its application and makes it possible to include it in formulations of semi-finished products $[18,19]$. DDW is a promising component in the technology of marzipan pastes of various types as it is determined by its amino acid composition and functional and processing properties $[18,19]$.

The results obtained in a series of our own technological experiments with various DDW fractions partially replacing almond flour in production of marzipan pastes have made it possible to reveal the fact of improvement of sensory characteristics such as appearance, color, consistency. At the same time, certain problems found in shaping marzipan pastes containing DDW were caused by an excessive growth of their stickiness. An experimentally established fact has shown feasibility of search for surfactants capable to improve formability of marzipan pastes containing DDW [20].

Analysis of literature and patent sources has shown technological feasibility of using glycerin in sugar pastes to reduce their stickiness (adhesion). It improves formability, makes the pastes more plastic when preparing ornamenting semi-finished products [21, 22]. Based on theoretical studies and a series of in-process experiments, technological feasibility of using glycerin as a surfactant in confectionery pastes containing DDW has been established [23]. It is also important to experimentally justify technological feasibility and rational concentration of glycerin used in composition of marzipan pastes containing DDW.

It was established from a series of well-substantiated considerations that it is feasible to create technologies of procurable marzipan pastes with reduced content of high-value nut raw materials possessing a set of predictable properties for their further widespread use in confectionery technologies. DDW is known to have obvious economic benefits as its market average price is 16 times less than that of almond flour.

To confirm effectiveness of use of DDW and glycerin in formulation of marzipan pastes, it is necessary to establish their effect on functional and processing properties (a complex of surface, rheological and sensory properties). Studies in the model paste systems containing DDW partially substituting almond flour in accordance with the developed differentiated reference scales of organoleptic evaluation of marzipan pastes of various technological purpose are required. It is also important to determine 
range of rational concentrations of formulation components that will ensure specified rheological, surface and sensory characteristics of marzipan pastes of various technological purposes. This determines relevance and objective of this scientific study.

\section{The aim and objectives of the study}

The study objective consists in determining rational DDW concentration in formulations of marzipan pastes to provide specified (desired) rheological, surface and sensory characteristics.

To achieve this objective, the following tasks were solved:

- to determine main rheological and sensory characteristics of marzipan pastes in the range of rational DDW concentrations;

- to study surface properties of marzipan pastes with DDW in relation with contact time and adhesion strength;

- to study influence on adhesive and cohesive interaction of formulation components, sensory characteristics of marzipan pastes with DDW and substantiate rational concentration of glycerin in composition of such pastes of various technological purposes;

- to determine rational content of DDW and glycerin in the composition of marzipan pastes which will ensure specified rheological, surface and sensory characteristics of marzipan pastes of various technological purposes.

\section{Materials and methods used in the study of rheological, surface and sensory properties of marzipan pastes}

The study subjects:

- dry demineralized whey prepared of curd whey at a $90 \%$ demineralization level according to Specification TU U 15.5-00413890-089:2014 (Table 1);

- marzipan paste made according to a conventional technology;

- model systems of marzipan pastes with addition of DDW in concentrations of $10 \ldots 40 \%$ (Table 2) and food glycerin (Specification TU U 10.8-40570177-001:2016) in concentrations of $1 \ldots 6 \%$ (Table 3 ) of the total mass of dry components of the marzipan mass (almond kernel and powdered sugar).

Table 1

Physical-chemical and organoleptic parameters of DDW

\begin{tabular}{|c|c|}
\hline Index name & Characteristics and norm \\
\hline Taste and smell & $\begin{array}{c}\text { Sweet, with no foreign aftertaste } \\
\text { and smell }\end{array}$ \\
\hline Appearance and consistency & Fine-dispersed powder \\
\hline Color & Lightly crème-colored \\
\hline $\begin{array}{c}\text { Weight content of dry } \\
\text { matters, \% }\end{array}$ & 97.00 \\
\hline Weight content of ash, \% & 2.63 \\
\hline Weight content of lactose, $\%$ & 75.92 \\
\hline Weight content of fat, \% & 1.0 \\
\hline Weight content of protein, $\%$ & 15.45 \\
\hline Titrated acidity & 4.7 \\
\hline Active acidity & 5.825 \\
\hline Index of solubility & Complete solubility \\
\hline
\end{tabular}

Table 2

Formulation composition of model systems of marzipan pastes per $100 \mathrm{~g}$

\begin{tabular}{|c|c|c|c|c|c|}
\hline \multirow{2}{*}{ Raw material name } & \multirow{2}{*}{$\begin{array}{l}\text { Control } \\
\text { sample }\end{array}$} & \multicolumn{5}{|c|}{$\begin{array}{c}\text { Samples with addition of } \\
\text { DDW, \% }\end{array}$} \\
\cline { 3 - 6 } & & 10 & 20 & 30 & 40 \\
\hline Powdered sugar & 43.0 & 38.0 & 33.0 & 28.0 & 23.0 \\
\hline Molasses & 14.0 & 14.0 & 14.0 & 14.0 & 14.0 \\
\hline DDW & - & 10.0 & 20.0 & 30.0 & 40.0 \\
\hline
\end{tabular}

Table 3

Formulation composition of model systems of marzipan pastes with DDW per $100 \mathrm{~g}$

\begin{tabular}{|c|c|c|c|c|c|c|}
\hline \multirow{2}{*}{ Raw material name } & \multicolumn{7}{|c|}{ Samples with addition of glycerin, \% } \\
\cline { 2 - 8 } & 1 & 2 & 3 & 4 & 5 & 6 \\
\hline \multicolumn{7}{|c|}{ DDW, $20 \%$} \\
\hline Almond kernel & 32.5 & 32.0 & 31.5 & 31.0 & 30.5 & 30.0 \\
\hline Powdered sugar & 32.5 & 32.0 & 31.5 & 31.0 & 30.5 & 30.0 \\
\hline Molasses & 14.0 & 14.0 & 14.0 & 14.0 & 14.0 & 14.0 \\
\hline DDW & 20.0 & 20.0 & 20.0 & 20.0 & 20.0 & 20.0 \\
\hline Glycerin & 1.0 & 2.0 & 3.0 & 4.0 & 5.0 & 6.0 \\
\hline \multicolumn{7}{|c|}{ DDW, 30\% } \\
\hline Almond kernel & 27.5 & 27.0 & 26.5 & 26.0 & 25.5 & 25.0 \\
\hline Powdered sugar & 27.5 & 27.0 & 26.5 & 26.0 & 25.5 & 25.0 \\
\hline Molasses & 14.0 & 14.0 & 14.0 & 14.0 & 14.0 & 14.0 \\
\hline DDW & 30.0 & 30.0 & 30.0 & 30.0 & 30.0 & 30.0 \\
\hline Glycerin & 1.0 & 2.0 & 3.0 & 4.0 & 5.0 & 6.0 \\
\hline
\end{tabular}

Sensory analysis of model compositions of marzipan pastes was performed at the Department of Technology and Organization of Restaurant Business of Kyiv National Trade and Economics University (KNTEU, Ukraine) by a tasting commission of 15 tasters who possessed professional knowledge, sensory ability, knowledge of properties of tested products and the process of their manufacture.

Sensory properties of model systems of marzipan pastes were determined according to the specially elaborated scales of organoleptic descriptors (Table 4). Marzipan pastes with DDW are used for topping or spreading interlayers in confectionery products (hereinafter referred to as TICP), production of chocolates and figured products (hereinafter referred to as CFP). Given the versatility of application of marzipan pastes, sensory characteristics of consistency have different factors of ponder ability according to the field of their technological use.

As a result of mathematical processing of the sensor analysis data, average value of quality indices was obtained taking into account the factor of ponder ability. Factors of ponder ability were determined by the expert method under the following conditions:

$$
\sum_{i=1}^{n} m_{i j}=1
$$

where $m_{i j}$ is the factor of ponder ability of the $i$-th index of the $j$-th group $\left(m_{i}>0\right) ; n$ is the number of product quality indices.

The factor of ponder ability $m_{i j}$ is determined from formula: 


$$
m_{i j}=\frac{m_{i j \mathrm{cp}}}{\sum_{i=1}^{n} m_{i j \mathrm{cp}}}
$$

where $m_{i j \mathrm{cp}}$ is the arithmetic mean of expert estimates of the $i$-th quality index of the $j$-th group.

The average value of $m_{i j \mathrm{cp}}$ was determined from formula:

$$
m_{i j \mathrm{cp}}=\frac{1}{N} \sum_{z=1}^{N} m_{i j z}, \quad(z=1,2,3, \ldots, N),
$$

where $N$ is the number of experts; $m_{i j z}$ is the estimate of the $i$-th quality index of the $j$-th group given by the $z$-th expert $(z=1,2,3, \ldots, N)$.

Rheological properties of the control and test samples were studied by means of a plane-parallel plastomer of
Tolstoy modification. It is based on determination of shear strain in relation to the specimen thickness under constant stress [24]. Fixed load (65 g) was taken for all variants and the same temperature $\left(+6{ }^{\circ} \mathrm{C}\right)$ and height $(7 \mathrm{~mm})$ of the samples were provided during the study of rheological characteristics of the model systems.

Surface characteristics of the control and test specimens were determined by means of a dynamometer connected to the MIG-1.3 measuring instrument which makes it possible to characterize degree of adhesion of materials having different structure in their surface contact. Strength of adhesion and cohesion was measured by the method of normal separation of the steel plate from the structured body (marzipan paste). Measurement data were displayed as a graph in the "force/time" coordinates.

Table 4

\begin{tabular}{|c|c|c|c|c|c|c|c|}
\hline \multirow{2}{*}{$\begin{array}{l}\text { Complex } \\
\text { indices }\end{array}$} & \multicolumn{2}{|c|}{$\begin{array}{l}\text { Factor of ponder } \\
\text { ability }\end{array}$} & \multirow{2}{*}{$\begin{array}{l}\text { Individual } \\
\text { indices }\end{array}$} & \multicolumn{2}{|c|}{$\begin{array}{l}\text { Factor of ponder } \\
\text { ability }\end{array}$} & \multirow{2}{*}{ Characteristics } & \multirow{2}{*}{$\begin{array}{l}\text { Quality level, } \\
\text { points }\end{array}$} \\
\hline & TICP & CFP & & TICP & CFP & & \\
\hline 1 & 2 & 3 & 4 & 5 & 6 & 7 & 8 \\
\hline \multirow{6}{*}{$\begin{array}{l}\text { Appear- } \\
\text { ance }\end{array}$} & \multirow{6}{*}{0.2} & \multirow{6}{*}{0.2} & \multirow{5}{*}{ Color } & \multirow{5}{*}{1.0} & \multirow{5}{*}{1.0} & $\begin{array}{c}\text { Barely perceptible coloring intensity, light } \\
\text { cream color }\end{array}$ & 5 \\
\hline & & & & & & $\begin{array}{l}\text { Slightly perceptible coloring intensity, light } \\
\text { cream color }\end{array}$ & 4 \\
\hline & & & & & & Perceptible coloring intensity, cream color & 3 \\
\hline & & & & & & $\begin{array}{l}\text { Strong coloring intensity, dark cream color } \\
\text { with yellowish tint }\end{array}$ & 2 \\
\hline & & & & & & Very strong coloring intensity, yellow & 1 \\
\hline & & & - & 1.0 & 1.0 & - & - \\
\hline \multirow{16}{*}{$\begin{array}{l}\text { Taste and } \\
\text { smell }\end{array}$} & \multirow{16}{*}{0.2} & \multirow{16}{*}{0.2} & \multirow{5}{*}{$\begin{array}{l}\text { Expres- } \\
\text { siveness }\end{array}$} & \multirow{5}{*}{0.4} & \multirow{5}{*}{0.4} & Strong & 5 \\
\hline & & & & & & Moderate & 4 \\
\hline & & & & & & Slightly perceptible & 3 \\
\hline & & & & & & Barely perceptible & 2 \\
\hline & & & & & & Absent & 1 \\
\hline & & & \multirow{5}{*}{ Saturation } & \multirow{5}{*}{0.3} & \multirow{5}{*}{0.3} & Strong & 5 \\
\hline & & & & & & Moderate & 4 \\
\hline & & & & & & Slightly perceptible & 3 \\
\hline & & & & & & Barely perceptible & 2 \\
\hline & & & & & & Absent & 1 \\
\hline & & & \multirow{5}{*}{ Balance } & \multirow{5}{*}{0.3} & \multirow{5}{*}{0.3} & Excellent & 5 \\
\hline & & & & & & Good & 4 \\
\hline & & & & & & Satisfactory & 3 \\
\hline & & & & & & Unsatisfactory & 2 \\
\hline & & & & & & Poor & 1 \\
\hline & & & - & 1.0 & 1.0 & - & - \\
\hline
\end{tabular}

Point scale of organoleptic evaluation of quality of model marzipan paste compositions with DDW 
Continuation of Table 4

\begin{tabular}{|c|c|c|c|c|c|c|c|}
\hline 1 & 2 & 3 & 4 & 5 & 6 & 7 & 8 \\
\hline \multirow{21}{*}{$\begin{array}{l}\text { Consis- } \\
\text { tency }\end{array}$} & \multirow{21}{*}{0.4} & \multirow{21}{*}{0.2} & \multirow{5}{*}{$\begin{array}{l}\text { Thickness, } \\
\text { strength }\end{array}$} & \multirow{5}{*}{0.1} & \multirow{5}{*}{0.3} & Moderately thick & 5 \\
\hline & & & & & & Thickened & 4 \\
\hline & & & & & & Thick & 3 \\
\hline & & & & & & Very thick & 2 \\
\hline & & & & & & Hard & 1 \\
\hline & & & \multirow{5}{*}{ Stickiness } & \multirow{5}{*}{0.1} & \multirow{5}{*}{0.3} & Average & 5 \\
\hline & & & & & & Moderate & 4 \\
\hline & & & & & & Satisfactory & 3 \\
\hline & & & & & & High & 2 \\
\hline & & & & & & Too high & 1 \\
\hline & & & \multirow{5}{*}{ Softness } & \multirow{5}{*}{0.1} & \multirow{5}{*}{0.2} & Moderately soft & 5 \\
\hline & & & & & & Slightly soft & 4 \\
\hline & & & & & & Moderately hard & 3 \\
\hline & & & & & & Hard & 2 \\
\hline & & & & & & Too hard & 1 \\
\hline & & & \multirow{5}{*}{$\begin{array}{l}\text { Spread } \\
\text { ability }\end{array}$} & \multirow{5}{*}{0.7} & \multirow{5}{*}{0.2} & Excellent & 5 \\
\hline & & & & & & Good & 4 \\
\hline & & & & & & Average & 3 \\
\hline & & & & & & Weak & 2 \\
\hline & & & & & & Very weak & 1 \\
\hline & & & - & 1.0 & 1.0 & - & - \\
\hline \multirow{6}{*}{$\begin{array}{l}\text { Formabil- } \\
\text { ity }\end{array}$} & \multirow{6}{*}{0.2} & \multirow{6}{*}{0.4} & \multirow{5}{*}{$\begin{array}{c}\text { Degree of } \\
\text { manifesta- } \\
\text { tion }\end{array}$} & \multirow{5}{*}{1.0} & \multirow{5}{*}{1.0} & Excellent & 5 \\
\hline & & & & & & Good & 4 \\
\hline & & & & & & Satisfactory & 3 \\
\hline & & & & & & Unsatisfactory & 2 \\
\hline & & & & & & $\mathrm{Bad}$ & 1 \\
\hline & & & - & 1.0 & 1.0 & 1.0 & - \\
\hline
\end{tabular}

Experimental studies were conducted in conditions of 5 times repeated measurements. The results obtained were statistically processed using standard Microsoft Office software package [24].

The fields of search for optimal weight fractions of DDW and glycerin in marzipan pastes were determined using the multifactorial experiment method.

\section{The results obtained in the studies of model compositions of marzipan pastes}

5. 1. The study of influence of dry demineralized whey on rheological and sensory characteristics of marzipan pastes

Strain characteristics of model systems of marzipan pastes (total, reversible, irreversible, relative strain) were determined. The experimental data were expressed in a form of fluidity curves by plotting dependence of relative strain $\gamma=f(t)$ (Fig. 1).

Regression analysis of intensity of strain in time was performed separately over two time intervals. In the period of intense paste strain $(0 \ldots 30 \mathrm{~min})$, change in time of fluidity of model compositions of marzipan pastes of various DDW content is described by the equations:

Control sample, $y=0.007 \tau^{3}-10.57 \tau^{2}+11.39 \tau+85.62$, (4)

DDW, $10 \%, y=0.003 \tau^{3}-0.12 \tau^{2}+12.56 \tau+96.07$,

DDW, $20 \%, y=0.002 \tau^{3}-0.13 \tau^{2}+14.75 \tau+96.79$,

DDW, $30 \%, y=0.002 \tau^{3}-0.14 \tau^{2}+15.63 \tau+97.25$,

DDW, $40 \%, y=0.001 \tau^{3}-0.21 \tau^{2}+10.61 \tau+108.4$,

where $y$ is fluidity $\left(10^{-3}\right), \tau$ is time $(\times 60 \mathrm{~s})$.

In the time interval of $30 \ldots 90 \mathrm{~min}$, fluidity kinetics of model compositions of marzipan pastes changed linearly.

As can be seen from the marzipan paste fluidity curves (Fig. 1), control specimens with total strain of 248.0 were the most resistant to shear stress. Introduction of DDW in a concentration of $10 \%$ increased total strain by 1.2 times compared to that of control specimens and measured 310.0. Further, with an increase in DDW concentration, total strain increased gradually up to 330.0 for $20 \%, 348.6$ for $30 \%$ and 352.9 for $40 \%$. 


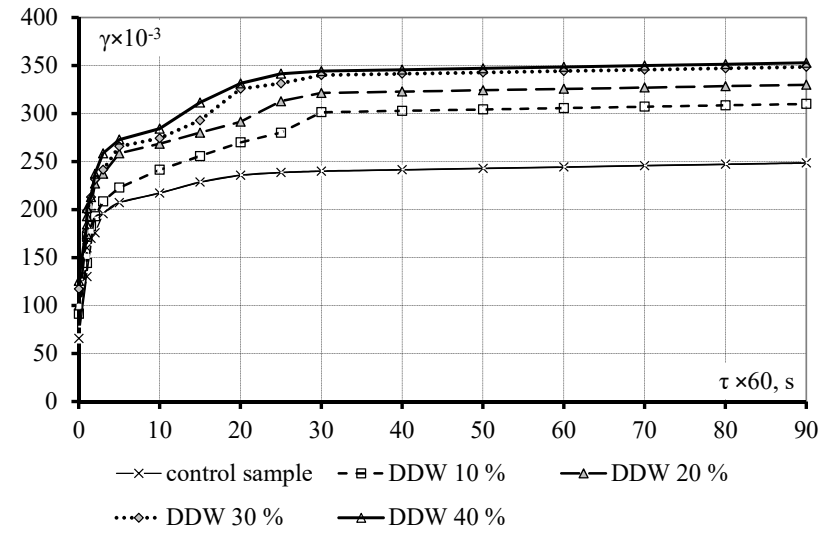

Fig. 1. Kinetics of fluidity curves for the model systems of marzipan pastes with various DDW content

Irreversible relative strain occurred as a result of development of viscous and plastic flow of the food mass of marzipan paste. In the case of viscous flow, strain was proportional to stress according to Newton's law and did not restore after load removal. Plastic strain occurred at a stress exceeding some limit value (fluidity boundary).The food system behaved as elastic one until this boundary was reached. Irreversible relative strain was stable for all marzipan paste samples under test. It was independent of the DDW concentration and measured 12.9. Accordingly, indices of reverse strain increased in a direct proportion to the indices of total strain within 235.7...340.0. Completely reversible relative strain disappeared after cessation of force and was equal to the sum of conditionally instantaneous and highly elastic strains.

Based on the strain characteristics of marzipan pastes, main rheological constants for the concentration range of DDW (conditionally instantaneous elastic modulus, highly elastic modulus, plastic viscosity and food system) were determined.

Dependence of the conditionally instantaneous modulus of elasticity on DDW concentration characterizing ability of the test samples to resist in proportion to strain was determined (Fig. 2). Introduction of DDW in the formulation of marzipan pastes caused a 1.2-1.6 times decrease in the modulus of elasticity compared to the control samples. A sharp decrease in elasticity was observed for DDW content of $10 \%$ and no significant changes occurred in the range of its content of $20 \ldots 40 \%$.

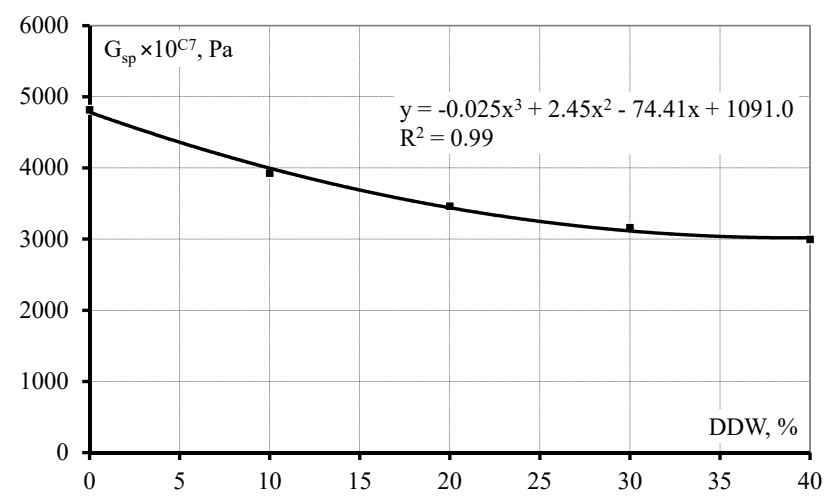

Fig. 2. Conditionally instantaneous modulus of elasticity of marzipan pastes containing DDW

Dependence of indices of the highly elastic module on DDW concentration characterizing cessation with time of strain in the studied samples after removal of stress (Fig. 3) was established. In dices of the highly elastic module preserved the tendency of the modulus of elasticity resulting in a 1.2-1.4 times decrease compared to the control sample.

At the same time, plastic viscosity (Fig. 4) characterizing the structured state property of flowing without destruction under the action of constant stress increased by 1.2 times with an increase in DDW concentration and was stable for all tested samples.

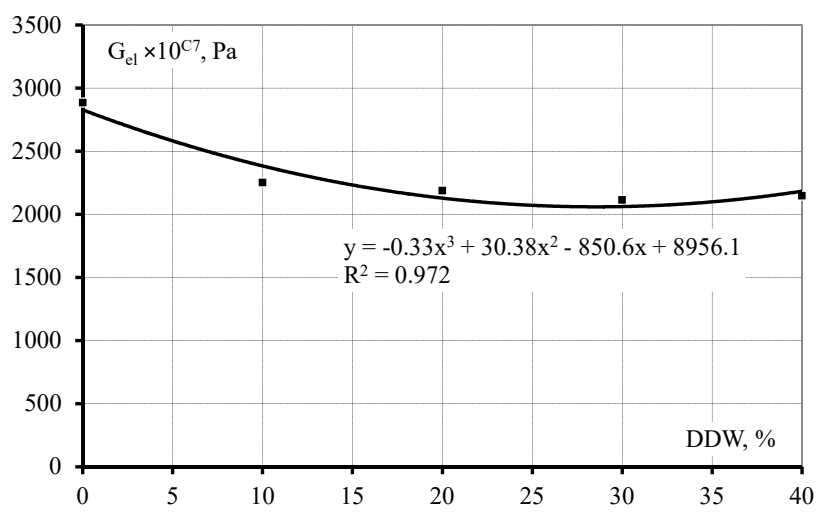

Fig. 3. Highly elastic modulus of marzipan paste containing DDW

DDW concentration of $10 \ldots 30 \%$ increased their compliance by $1.2 \ldots 1.4$ times but further concentration growth resulted in a decrease in this index (Fig. 5) which is consistent with the sensory characteristics (Table 5).

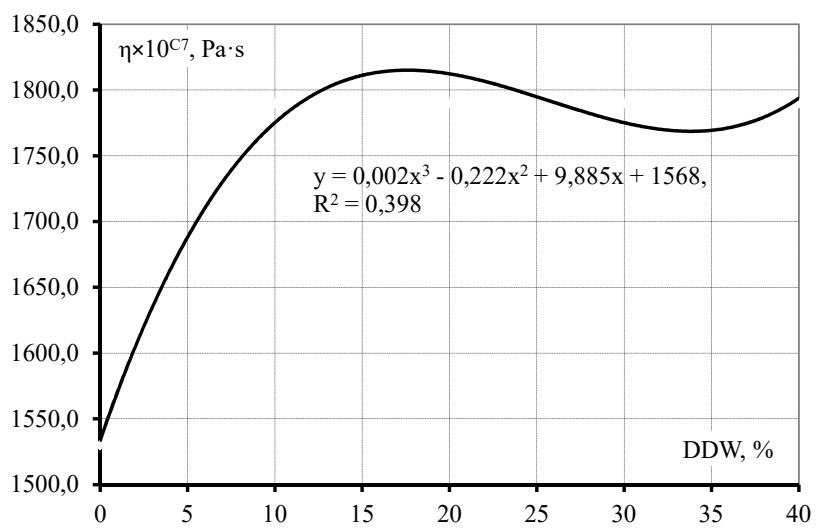

Fig. 4. Plastic viscosity of marzipan pastes containing DDW

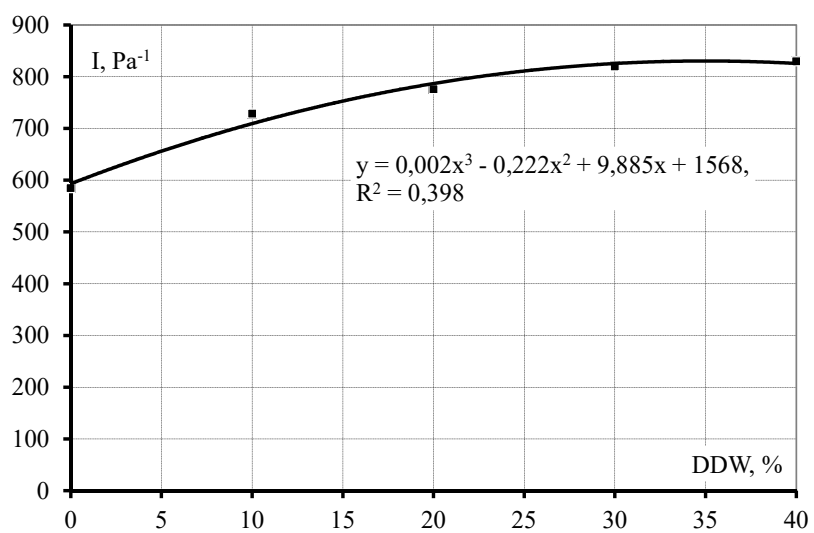

Fig. 5. Compliance of marzipan paste containing DDW 
Table 5

Organoleptic indices of the model compositions of marzipan pastes containing DDW

\begin{tabular}{|c|c|c|c|c|c|c|c|c|c|c|c|}
\hline \multirow{2}{*}{ Index name } & \multicolumn{2}{|c|}{$\begin{array}{c}\text { Ponder ability } \\
\text { factor }\end{array}$} & \multirow{2}{*}{ Characteristic } & \multirow{2}{*}{$\begin{array}{l}\text { Descriptor } \\
\text { number }\end{array}$} & \multicolumn{2}{|c|}{$\begin{array}{c}\text { Factor of ponder } \\
\text { ability }\end{array}$} & \multirow{2}{*}{$\begin{array}{l}\text { Control } \\
\text { sample }\end{array}$} & \multicolumn{4}{|c|}{ Samples with added DDW, \% } \\
\hline & TICP & CFP & & & TICP & CFP & & 10 & 20 & 30 & 40 \\
\hline Appearance & 0.2 & 0.2 & Color & 1 & 1.0 & 1.0 & 4.7 & 4.7 & 4.8 & 4.8 & 4.9 \\
\hline \multicolumn{7}{|c|}{ Total assessment according to TICP descriptors } & 4.7 & 4.7 & 4.8 & 4.8 & 4.9 \\
\hline \multicolumn{7}{|c|}{ Overall assessment according to TICP index } & 0.94 & 0.94 & 0.96 & 0.96 & 0.98 \\
\hline \multicolumn{7}{|c|}{ Total assessment according to CFP descriptors } & 4.7 & 4.7 & 4.8 & 4.8 & 4.9 \\
\hline \multicolumn{7}{|c|}{ Overall assessment according to CFP index } & 0.94 & 0.94 & 0.96 & 0.96 & 0.98 \\
\hline \multirow{3}{*}{$\begin{array}{l}\text { Taste and } \\
\text { smell }\end{array}$} & \multirow{3}{*}{0.2} & \multirow{3}{*}{0.2} & Expressiveness & 1 & 0.4 & 0.4 & 5.0 & 4.9 & 4.9 & 4.8 & 4.2 \\
\hline & & & Shining degree & 2 & 0.3 & 0.3 & 5.0 & 4.9 & 4.9 & 4.8 & 4.2 \\
\hline & & & Balance & 3 & 0.3 & 0.3 & 4.8 & 4.9 & 5.0 & 5.0 & 4.6 \\
\hline \multicolumn{7}{|c|}{ Total assessment according to TICP descriptors } & 4.94 & 4.90 & 4.90 & 4.86 & 4.32 \\
\hline \multicolumn{7}{|c|}{ Overall assessment according to TICP index } & 0.99 & 0.98 & 0.98 & 0.97 & 0.86 \\
\hline \multicolumn{7}{|c|}{ Total assessment according to CFP descriptors } & 4.94 & 4.90 & 4.90 & 4.86 & 4.32 \\
\hline \multicolumn{7}{|c|}{ Overall assessment according to CFP index } & 0.99 & 0.98 & 0.98 & 0.97 & 0.86 \\
\hline \multirow{4}{*}{ Consistency } & \multirow{4}{*}{0.4} & \multirow{4}{*}{0.2} & Density, strength & 1 & 0.1 & 0.3 & 4.2 & 4.1 & 3.8 & 3.6 & 3.4 \\
\hline & & & Stickiness & 2 & 0.1 & 0.3 & 4.2 & 3.8 & 3.4 & 3.0 & 2.6 \\
\hline & & & Softness & 3 & 0.1 & 0.2 & 4.2 & 4.1 & 3.8 & 3.6 & 3.4 \\
\hline & & & Spread ability & 4 & 0.7 & 0.2 & 3.5 & 4.5 & 5.0 & 4.7 & 4.5 \\
\hline \multicolumn{7}{|c|}{ Total assessment according to TICP descriptors } & 3.71 & 4.35 & 4.6 & 4.31 & 4.09 \\
\hline \multicolumn{7}{|c|}{ Overall assessment according to TICP index } & 1.48 & 1.74 & 1.84 & 1.72 & 1.63 \\
\hline \multicolumn{7}{|c|}{ Total assessment according to CFP descriptors } & 4.06 & 4.09 & 4.42 & 3.6 & 3.0 \\
\hline \multicolumn{7}{|c|}{ Overall assessment according to CFP index } & 0.8 & 0.81 & 0.88 & 0.72 & 0.6 \\
\hline Formability & 0.2 & 0.4 & $\begin{array}{l}\text { Degree of mani- } \\
\text { festation }\end{array}$ & 1 & 1.0 & 1.0 & 4.5 & 4.7 & 4.8 & 4.9 & 4.1 \\
\hline \multicolumn{7}{|c|}{ Total assessment according to TICP descriptors } & 4.5 & 4.7 & 4.8 & 4.9 & 4.1 \\
\hline \multicolumn{7}{|c|}{ Overall assessment according to TICP index } & 0.9 & 0.96 & 0.98 & 0.92 & 0.82 \\
\hline \multicolumn{7}{|c|}{ Total assessment according to CFP descriptors } & 4.5 & 4.7 & 4.8 & 4.9 & 4.1 \\
\hline \multicolumn{7}{|c|}{ Overall assessment according to CFP index } & 1.8 & 1.92 & 1.96 & 1.84 & 1.64 \\
\hline & & & eneral assessment, & $\mathrm{ICP}$ & & & 4.31 & 4.62 & 4.76 & 4.57 & 4.29 \\
\hline & & & eneral assessment, & $\mathrm{CFP}$ & & & 4.43 & 4.65 & 4.78 & 4.49 & 4.08 \\
\hline
\end{tabular}

5. 2. Studying surface properties of marzipan pastes with dry demineralized whey

Effect of DDW concentration on adhesion and cohesion strength of marzipan pastes (contact time: $5 \mathrm{~s}$ ) was studied (Table 6). Adhesion as a surface phenomenon is associated with rheological parameters and characterizes volumetric properties of marzipan pastes. It occurs at the interface of two phases of heterogeneous condensed bodies (the food mass is one phase and the contact surface is the second phase) and creates bond. Bulk properties of the masses themselves determine contact area of the two bodies affecting adhesion strength and its consequence characterizing the surface state after removal of the stuck mass.

Adhesion has concomitant phenomena that characterize bulk properties of food masses and significantly affect adhesive interaction of the paste components.

Influence of volumetric characteristics of the food masses on the surface properties can be traced by considering the ratio of adhesion to cohesion strength. In the case of adhesion, there is a phase distribution boundary and no such limit for cohesion. This is one of cohesion features, its fundamental distinction from adhesion. Cohesion strength characterizes the body resistance to destruction connected with overcoming forces of interaction between atoms and molecules on the interface and signifies bond within the marzipan paste, that is, within one phase.

Table 6

Strength of adhesion and cohesion of a marzipan paste containing DDW

\begin{tabular}{|c|c|c|}
\hline Index name & $\begin{array}{c}\text { Adhesion strength, } \\
\mathrm{N} / \mathrm{m}^{2}\end{array}$ & $\begin{array}{c}\text { Cohesion strength, } \\
\mathrm{N} / \mathrm{m}^{2}\end{array}$ \\
\hline Control sample & 21.07 & 15.9 \\
\hline With DDW, $10 \%$ & 37.75 & 37.11 \\
\hline With DDW, $20 \%$ & 39.28 & 39.12 \\
\hline With DDW, $30 \%$ & 43.83 & 41.01 \\
\hline With DDW, $40 \%$ & 45.88 & 41.06 \\
\hline
\end{tabular}

The studies of dependence of adhesion strength on DDW concentration have allowed us to establish a 1.7-2.1 times growth of this index compared to the marzipan paste prepared by a conventional technology. Introduction of DDW to the composition of marzipan pastes leads to a tighter structure and hence reduction of surface roughness and porosity that increases area of actual contact of the adhesive 
resulting in a growth of adhesive strength. Tensile strength (cohesion) increases 1.6 times compared to the control sample and is almost independent of DDW concentration which evidences strengthening of bonds between protein molecules.

The following is determination of dependences of adhesion strength on contact time $(2 \ldots 90 \mathrm{~s})$ in the DDW concentration range. They are represented by the graph (Fig. 6) and described by equations:

$$
\begin{aligned}
& \text { Control sample, } \\
& \omega=-0.0015 \tau^{2}+0.2102 \tau+20.391 ; R^{2}=0.9621,
\end{aligned}
$$

DDW, $10 \%, \omega=-0.0066 \tau^{2}+0.8682 \tau+35.679$; $R^{2}=0.9441$,

DDW, $20 \%, \omega=-0.0066 \tau^{2}+0.8451 \tau+38.209$; $R^{2}=0.9261$,

DDW, $30 \%, \omega=-0.007 \tau^{2}+0.9086 \tau+40.961$; $R^{2}=0.9294$,

DDW, $40 \%, \omega=-0.007 \tau^{2}+0.9007 \tau+43.338$; $R^{2}=0.9319$,

where $\omega$ is adhesion, $\mathrm{N} / \mathrm{m}^{2}, \tau$ is contact time, s.

Dependences of adhesion strength after holding the marzipan pastes for $2 \mathrm{~s}$ on the contact duration(for $2 \ldots 90 \mathrm{~s}$ ) in a range of DDW concentrations are represented by the graph (Fig. 7) and described by equations:

Control sample,

$\omega=0.0039 \tau^{2}-0.6326 \tau+24.519 ; R^{2}=0.8784$,

DDW, $10 \%, \omega=0.0032 \tau^{2}-0.4882 \tau+37.745$; $R^{2}=0.9956$,

DDW, $20 \%, \omega=0.0022 \tau^{2}-0.3521 \tau+38.909$; $R^{2}=0.9923$,

DDW, $30 \%, \omega=0.0021 \tau^{2}-0.2945 \tau+40.215$; $R^{2}=0.9798$,

DDW, $40 \%, \omega=0.0025 \tau^{2}-0.3326 \tau+42.726$; $R^{2}=0.9419$,

where $\omega$ is adhesion, $\mathrm{N} / \mathrm{m}^{2}, \tau$ is contact time, $\mathrm{s}$.

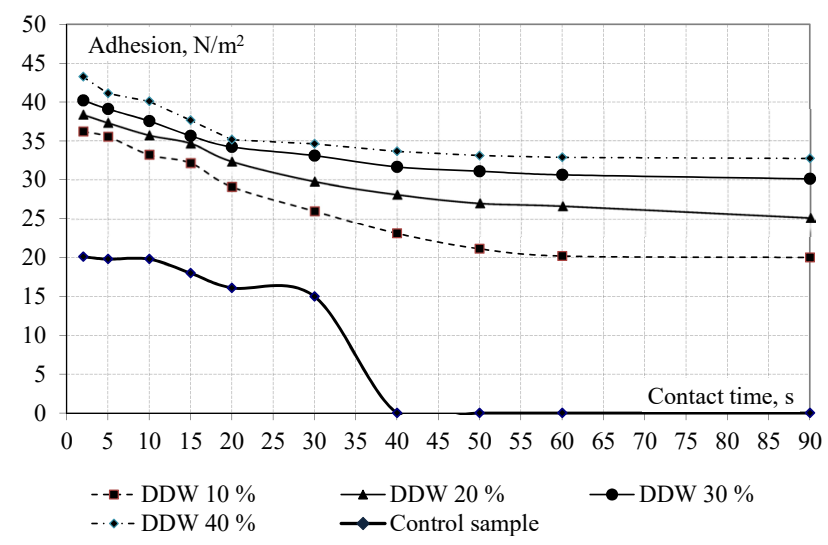

Fig. 6. Dependence of adhesion strength of marzipan pastes containing DDW on the contact duration

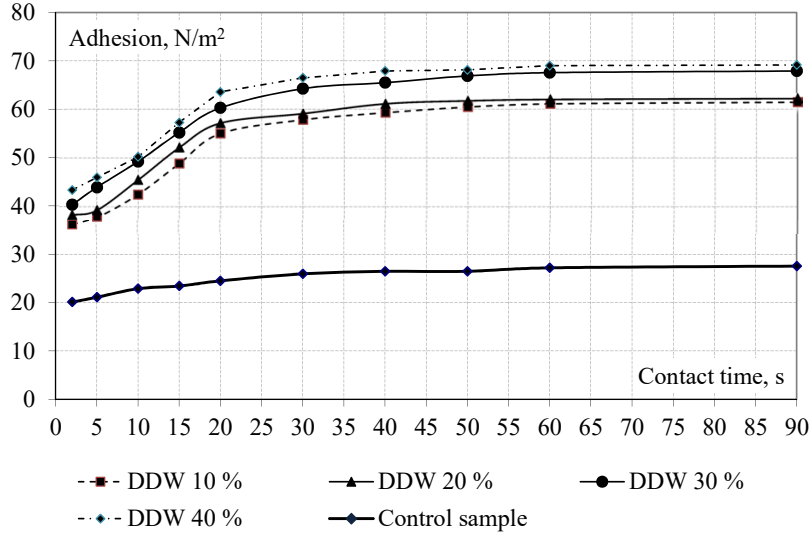

Fig. 7. Dependence of adhesion strength of marzipan pastes containing DDW on the time of contact with air

As DDW concentration and contact time increased adhesion strength did not increase in a direct proportion. For the contact time from 2 to $15 \mathrm{~s}$, adhesion strength increased rapidly but with further increase in contact time, it increased gradually, regardless of DDW concentration.

Adhesion strength of the marzipan paste prepared by conventional technology gradually decreased and disappeared by $60 \mathrm{~s}$ with an increase in time of contact with air. For the test specimens, adhesion was observed even at $90 \mathrm{~s}$ and did not depend on DDW concentration. From the point of view of industrial production, growth of adhesion-cohesion interaction is undesirable, so it is advisable to consider ways of regulating these properties. The adhesive properties of confectionery pastes can be controlled by the use of surfactants, in particular glycerin [23].

5. 3. Studying the influence of glycerin on surface and sensory characteristics of marzipan pastes containing dry demineralized whey

Influence of glycerin concentration in an amount of $1 \ldots 6 \%$ on adhesive strength of marzipan pastes with a $20 \ldots 30 \%$ DDW concentration was determined for contact time of $5 \mathrm{~s}$ ( Table 7 ).

Table 7

Adhesion strength of marzipan pastes with DDW and glycerin, $\mathrm{N} / \mathrm{m}$

\begin{tabular}{|c|c|c|c|c|c|c|c|}
\hline \multirow{2}{*}{ Index name } & \multicolumn{7}{|c|}{ Glycerin, \% } \\
\cline { 2 - 9 } & 0 & 1 & 2 & 3 & 4 & 5 & 6 \\
\hline DDW, $20 \%$ & 39.3 & 37.6 & 34.0 & 31.1 & 28.2 & 24.6 & 22.1 \\
\hline DDW, 30 \% & 43.8 & 39.1 & 37.1 & 33.5 & 29.5 & 25.1 & 23.0 \\
\hline
\end{tabular}

It was found that with an increase in glycerin concentration from 1 to $6 \%$, adhesive strength of marzipan pastes decreased from $39.3 \ldots 22.1 \mathrm{~N} / \mathrm{m}^{2}$ at DDW concentration of $20 \%$ and from $43.8 \ldots 23.0 \mathrm{~N} / \mathrm{m}^{2}$ at DDW concentration of $30 \%$. Adhesive strength decreased at glycerin concentration of $6 \%$ and approached that of marzipan pastes prepared by conventional technology.

However, in order to determine rational concentration of glycerin in the composition of marzipan pastes containing DDW, it is advisable to consider its effect on sensory characteristics.

According to the results of sensory analysis (Fig. 8), it is inadvisable to increase glycerin concentration above $5 \%$. 


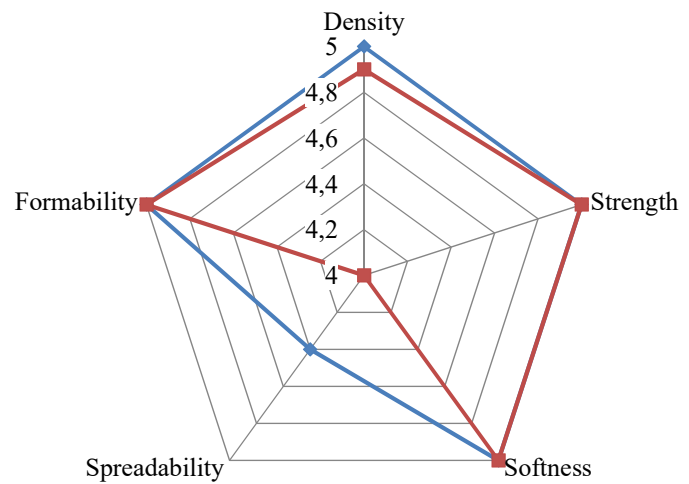

$$
\leadsto \text { TICP } \quad-\text { CFP }
$$

Fig. 8. Sensory characteristics of consistency of marzipan pastes containing DDW and glycerin

\section{4. Areas of search for rational concentrations of} formulation components of marzipan pastes

Proceeding from the studies of sensory and rheological characteristics, lines of technological use of marzipan pastes have been proposed based on structural properties. For TICP marzipan pastes intended for topping and spreading interlayers in wads and confectionery products where paste spread ability is the main index of consistency, the best indices were set for DDW concentration of $20 \%$.

For the CFP marzipan paste used in the manufacture of chocolates, candy sticks, bars as well as in molding of figured products where the main criterion for the consistency characteristic is the paste formability, the best indices were set for concentration of $30 \%$.

Zones of rational concentrations of DDW and glycerin in the composition of marzipan pastes were established by the method of compromise solutions (Fig. 9, 10).

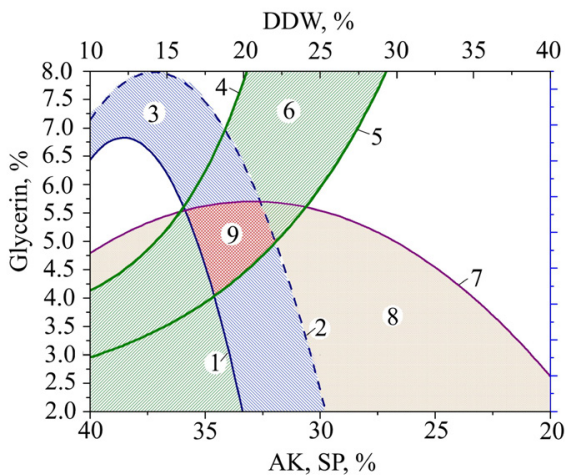

Fig. 9. Compromise optimal areas of glycerin content at a $20 \%$ DDW concentration in marzipan pastes: equality 17 , under condition of $Y 1_{\mathrm{TICP}}=3 b(1)$; equality 17 , under condition

of $Y 1_{\mathrm{TICP}}=4 b$ (2); $3 b \geq \mathrm{Y} 1_{\mathrm{TICP}} \geq 4 b$ (3); equality 19 , under condition $Y 2_{\mathrm{TICP}}=3 b(4)$; equality 19 , provided $Y 2_{\mathrm{TICP}}=4 b$ (5); $3 b \geq V_{\mathrm{TICP}} \geq 4 b(6)$; equality 21 , under condition of $Y 3_{\mathrm{TICP}}=4.5 \mathrm{~b}(7) ; Y_{\mathrm{TICP} \geq 4.5 \mathrm{~b}}(8)$; the area of compromise values $X_{1}$ and $X_{2}(9)$

Mathematical models describing dependence of rheological properties of the pastes on content of DDW and glycerin were constructed using an arbitrary experimental plan. This method is applied if polynomials of a certain type are selected as functions for model construction.

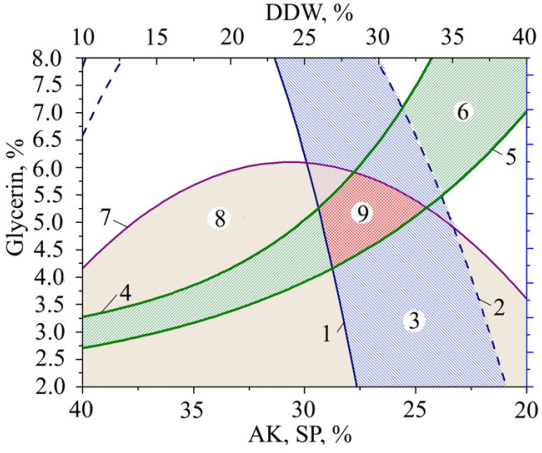

Fig. 10. Compromise optimal areas of glycerin content at a $30 \%$ DDW concentration in CFP marzipan pastes: equality

18 , under condition of $Y 1_{\mathrm{CFP}}=4 \mathrm{~b}$ (1); equality 18 , under

condition of $Y 1_{\mathrm{CFP}}=5 b(2) ; 4 b \geq Y 1_{\mathrm{CFP}} \geq 5 b$ (3); equality 20 , under condition of $Y 2_{\text {CFP }}=4 b(4)$; equality 20 , under condition

of $Y 2_{\mathrm{CFP}}=5 b(5) ; 4 b \geq Y 2_{\mathrm{CFP}} \geq 5 b(6)$; equality 22 , under

condition of $Y 3_{\mathrm{CFP}}=4.5 b(7) ; Y 3_{\mathrm{CFP}} \geq 4.5 b(8)$; the range of compromise values of $X_{1}, X_{2}$ and $X_{3}(9)$

Variable factors and optimization criteria were identified and a factor determining area was found. Main parameters of rheological properties include glycerin content $\left(X_{1}\right)$ and DDW content $\left(X_{2}\right)$, hence, contents of almond kernel $\left(X_{3}\right)$ and powdered sugar $\left(X_{4}=100-X_{1}-X_{2}-X_{3}\right)$ depend on the values of main factors.

Limitations of specified factors and their designation are given in Table 8.

Table 8

Parameters of search for optimal compromise areas of weight fraction of glycerin and DDW in marzipan pastes

\begin{tabular}{|c|c|c|c|c|}
\hline \multirow{2}{*}{$\begin{array}{l}\text { Desig- } \\
\text { nation }\end{array}$} & \multirow[b]{2}{*}{ Factor } & \multirow[b]{2}{*}{ Unit } & \multicolumn{2}{|c|}{ Limitation in axes } \\
\hline & & & $\begin{array}{c}\text { TICP marzipan } \\
\text { paste }\end{array}$ & $\begin{array}{l}\text { CFP marzipan } \\
\text { paste }\end{array}$ \\
\hline $\begin{array}{l}Y 1_{\mathrm{TICP}}, \\
Y 1_{\mathrm{CFP}},\end{array}$ & Strength & points & $4 \geq Y 1_{\mathrm{TICP}} \geq 3$ & $5 \geq Y 1_{\mathrm{CFP}} \geq 4$ \\
\hline $\begin{array}{l}Y 2_{\text {TICP, }} \\
Y 2_{\text {CFP }}\end{array}$ & $\begin{array}{l}\text { Spread } \\
\text { ability }\end{array}$ & points & $4 \geq Y 2_{\mathrm{TICP}} \geq 3$ & $5 \geq Y 2_{\mathrm{CFP}} \geq 4$ \\
\hline$Y 3$ & Formability & points & $Y 3 \geq 4.5$ & $Y 3 \geq 4.5$ \\
\hline
\end{tabular}

When planning an experiment to study change of rheological parameters of marzipan pastes, the mixture factors characterizing ratio of main components of the mixed composition were selected, namely: $x_{1}$ for content of almond kernel (AK) and sugar powder (SP), wt. \%; $x_{2}$ for glycerin content; wt. $\% ; x_{3}$ for DDW content, wt. $\%$.

Previous experimental studies of influence of components of marzipan pastes on their rheological properties have made it possible to establish the area of experimental organization to obtain dependences of the form $Y=\int\left(x_{i}\right)$ at $i=3$. The center of the orthogonal plan was at points $x_{1}=30$; $x_{2}=4.75 ; x_{3}=25$ with measurement intervals of $\pm 2.5, \pm 0.5$, \pm 3.75 , respectively.

According to the experiment plan, 16 model compositions were developed.

In order to obtain mathematical descriptions of dependences in terms of the indices by which the obtained marzipan pastes were tested, regression analysis of the obtained array of experimental data was performed. This has resulted in mathematical equations describing influence of marzipan paste components on rheological properties. 
Mathematical models of strength:

$$
\begin{aligned}
& Y 1_{\mathrm{TICP}}=-2.35 x_{1}^{2}-1.25 x_{2}^{2}-3.14 x_{3}^{2}+ \\
& +0.13 x_{1} x_{2}-1.52 x_{1} x_{3}+0.89 x_{2} x_{3}+ \\
& +7.27 x_{1}+4.81 x_{2}-6.73 x_{3}+21.07 \\
& Y 1_{\mathrm{CFP}}=-1.08 x_{1}^{2}-0.48 x_{2}^{2}-0.26 x_{3}^{2}+ \\
& +0.09 x_{1} x_{2}-0.87 x_{1} x_{3}+1.02 x_{2} x_{3}+ \\
& +5.48 x_{1}+3.48 x_{2}-4.27 x_{3}+7.12 .
\end{aligned}
$$

Mathematical models in terms of spread ability:

$$
\begin{aligned}
& Y 2_{\mathrm{TICP}}=11.6 \times 10^{0.41 x_{1}}-0.05 x_{2}^{2}-2.12 x_{3}^{2}+ \\
& +4.67 x_{1} x_{2}-2.37 x_{1} x_{3}+0.16 x_{2} x_{3}+ \\
& +9.67 x_{1}+0.44 x_{2}-7.56 x_{3}+97.14 \\
& Y 2_{\mathrm{CFP}}=18.6 \times 10^{0.27 x_{1}}-1.08 x_{2}^{2}-0.67 x_{3}^{2}+ \\
& +3.44 x_{1} x_{2}-1.04 x_{1} x_{3}+0.78 x_{2} x_{3}+ \\
& +4.41 x_{1}+5.48 x_{2}-6.12 x_{3}+122.12 .
\end{aligned}
$$

Mathematical models in terms of formability:

$$
\begin{aligned}
& Y 3_{\mathrm{TICP}}=-0.18 x_{1}^{2}-0.73 x_{2}^{2}-2.61 x_{3}^{2}+ \\
& +0.04 x_{1} x_{2}-2.94 x_{1} x_{3}+7.45 x_{2} x_{3}+ \\
& +2.45 x_{1}-3.57 x_{2}+1.54 x_{3}+2.8 \\
& Y 3_{\mathrm{CFP}}=-0.15 x_{1}^{2}-0.46 x_{2}^{2}-3.07 x_{3}^{2}+ \\
& +2.01 x_{1} x_{3}+6.37 x_{2} x_{3}+1.76 x_{1}- \\
& -2.31 x_{2}+1.04 x_{3}+3.9
\end{aligned}
$$

where $Y 1_{\mathrm{TICP}}$ is strength of marzipan paste, points; $Y 1_{\mathrm{CFP}}$ is strength of the CFP marzipan paste, points; $Y 2_{\mathrm{TICP}}$ isspreadability of TICP marzipan paste, points; $Y 2_{\mathrm{CFP}}$ is spread ability of CFP marzipan paste, points; $Y 3$ is formability, points; $X_{1}$ is $\mathrm{AK}$ and $\mathrm{SP}$ content, $\% ; X_{2}$ is glycerin content, $\% ; X_{3}$ is DDW content, \%.

The mathematical models obtained have made it possible to graphically determine optimal ratio of marzipan paste components (Table 9).

Table 9

Parameters of optimization of rheological properties of marzipan pastes

\begin{tabular}{|c|c|c|c|}
\hline $\begin{array}{c}\text { Optimization } \\
\text { criteria }\end{array}$ & $\begin{array}{c}\text { Strength }(Y 1), \\
\text { points }\end{array}$ & $\begin{array}{c}\text { Spread } \\
\text { ability }(Y 2), \\
\text { points }\end{array}$ & $\begin{array}{c}\text { Formability }(Y 3), \\
\text { points }\end{array}$ \\
\hline $\begin{array}{c}\text { Minimum } \\
\text { value }\end{array}$ & 4 & 4 & $\geq 4.5$ \\
\hline $\begin{array}{c}\text { Maximum } \\
\text { value }\end{array}$ & 5 & 5 & \\
\hline
\end{tabular}

Graphical dependences of quality indices on the content of components were constructed for each paste type in a system with three coordinate scales. Since contents of almond kernel $\left(X_{\mathrm{AK}}\right)$ and sugar powder $\left(X_{\mathrm{SP}}\right)$ are inversely dependent on the content of other components, content of DDW $\left(X_{2}\right)$ and the sum of AK and SP fraction
$\left(X_{3}=X_{\mathrm{AK}}+X_{\mathrm{SP}}\right)$ were placed on opposite interdependent axes with count in opposite directions.

\section{Discussion of the results obtained in studying model compositions of marzipan pastes}

Rheological characteristics determine ability of marzipan pastes to resist strains under the action of external forces acting during processing and are common characteristic properties that determine possibility of their processing. Structured systems of marzipan pastes have a complex of rheological characteristics characterized by modular constants such as elastic modulus, highly elastic modulus, viscosity of elastic aftereffect, plastic viscosity, and food system compliance.

According to the study results, it was found that partial replacement of almond flour with DDW in the formulation composition of marzipan pastes leads to a change in structural state and quantitative values of rheological and sensory characteristics. It has been experimentally established that with an increase in weight fraction of DDW from $10 \ldots 30 \%$, indices of inverse strain characteristics, namely the modulus of elasticity (Fig. 2) decrease by 1.2...1.6 times (547...334 Pa) and highly elastic modulus (Fig. 3) decrease by $1.2 \ldots 1.4$ times $(244 \ldots 199 \mathrm{~Pa})$ compared to the control sample. At the same time, plastic viscosity indices (Fig. 4) increase by 1.2 times which results in a growth of formability of model compositions of marzipan pastes (Table 5).

According to the results of sensory analysis of consistency of model compositions of marzipan pastes with $10 \ldots 30 \%$ of DDW, their formability increases due to the increase in strength and density and, accordingly, the decrease in softness. With an increase in DDW concentration to $20 \%$, spread ability indices improve and a further increase in DDW concentration leads to a decrease in this index due to compaction of the marzipan pastes structure. However, growth of DDW fraction in marzipan pastes by more than $30 \%$ is impractical because of a significant increase in stickiness of marzipan pastes, compaction of their spatial framework, loss of plasticity, decrease in flexibility and, subsequently, change of a pasty structure to a solid one (Table 6). Strengthening of the spatial framework of model compositions of marzipan pastes containing DDW is explained by the increase in protein content in them and their functional properties, first of all, their ability to hydrate. It is known that mobility, reproducibility and relatively low strength of coagulation contacts of particles in the structure of marzipan pastes are associated with preservation of very thin residual layers of liquid dispersion medium between particles in adhesion locations. Strengthening of spatial framework of the model compositions of marzipan pastes containing DDW is probably due to the high adsorption properties of the DDW protein component. Therefore, when using DDW, thin interlayers of the dispersion medium in the structure of marzipan pastes are reduced which causes an increase in molecular forces of adhesion and strengthens coagulation contacts between particles. Taking into account the results of sensory studies, it was found that the best characteristics are inherent in the samples of the marzipan paste using DDW within $10 \ldots 20 \%$.

As a result of sensory analysis of appearance indices, a positive influence of DDW on color of model compositions of marzipan pastes was established. When DDW concentration increases, cream color intensity decreases which 
facilitates toning of marzipan pastes to obtain the specified color range (Table 6). It has been established that DDW in a $10 . .20 \%$ concentration not only harmoniously complements but also emphasizes almond taste and aroma of marzipan pastes. At DDW concentration of $30 \%$, a light milky tint appears while a moderately pronounced and saturated typical marzipan taste and aroma are maintained while creating an optimally balanced almond-milk composition (Table 6). Milk taste is dominating at DDW concentration of $40 \%$ while weakly expressed almond taste is preserved, so it is not recommended to raise DDW concentration in compositions of marzipan pastes higher than $30 \%$ to preserve typical almond taste and aroma (Table 6).

Therefore, results from a series of rheological and sensory studies confirmed the possibility of introducing DDW in formulations of marzipan pastes at a concentration of $10 \ldots 20 \%$, which improves their sensory, technological and functional properties. However, in order to achieve technological goals of reducing cost of marzipan paste products, ensure import independence of their production while providing high functional and technological and sensory properties, high nutritional value, technological feasibility of increasing fraction of DDW in the CFP to $30 \%$ was established. This necessitated solution of the problem of additional use of surfactants in compositions of marzipan pastes to improve mobility of adsorption layers and reduce strength of the structure.

Adhesion strength grows with an increase in DDW concentration which is confirmed by sensory studies and a significant growth of stickiness. Studies of surface properties of pastes depending on the time of contact with an adhesive and air confirmed the fact of prolongation of work with the paste which is a very important factor in manual production of figured decorative semi-finished products. However, in industrial production of marzipan masses, in particular, forming marzipan chocolates, increased adhesion has negative consequences. Adhesion is manifested by marzipan masses sticking to the equipment causing growth of power consumption and worsening of product quality. To ensure stability of operation of the process equipment conventionally used in the production process, it is important to control strength of marzipan pastes containing DDW which is possible through the use of glycerin.

It has been experimentally established that introduction of $4 \ldots 5 \%$ glycerin in the formulation of marzipan pastes with DDW enables reduction of adhesion strength and brings it closer to that of the control sample. However, growth of concentration leads to weakening of spatial frame and destruction of pasty structure. With introduction of glycerin and increase in its concentration in the composition of marzipan TICP paste, the main index consistency, that is elongation, gradually decreases, so it is impractical to raise concentration of glycerin by more than $5 \%$. This is also confirmed by the results of sensory analysis (Fig. 10).

Introduction of glycerin in the composition of the CFP marzipan paste leads to the paste softening which makes it more pliable in the process of manufacture of semi-finished products while maintaining high formability. Increase in concentration of glycerin by more than $5 \%$ contributes to formation of a very soft, almost fluid consistency resulting in a loss of formability.

The study results confirmed that $20 \ldots 30 \%$ of dry components of marzipan paste, namely powdered sugar and almond nut can be replaced by DDW. It has been experimentally found that this concentration of DDW makes it possible to improve rheological characteristics of marzipan pastes. Component compatibility of formulation ingredients has been established for the given concentration of DDW which makes it possible to preserve exclusivity of organoleptic properties of marzipan pastes. Expediency of using glycerin at a concentration of $5 \%$ of the total mass of marzipan paste has been confirmed. This ensures surface properties close to marzipan pastes prepared by a conventional technology. The established concentration makes it possible to reduce power consumption by $29 . .35 \%$ in manufacture of finished products, primarily by changing qualitative carbohydrate composition as well as increasing their biological value by raising the content of whole protein 1.4 times and balancing amino acid composition which was confirmed by previous studies [20].

Further studies are aimed at substantiation of rational mode and parameters of production of marzipan pastes containing DDW, indices of safety, quality and rational shelf life, technology of use of marzipan pastes in confectionery production.

\section{Conclusions}

1. The study results show that introduction of DDW leads to a change in the structural state of marzipan pastes, improves their technological and functional properties. Experimental data confirmed growth of plastic strains and decrease inelastic-plastic ones. It was established that marzipan pastes containing $20 \ldots 30 \%$ DDW have rational boundaries of rheological properties while providing desired sensory characteristics.

2. According to the results obtained in the study of surface properties at contact time of $2 \ldots 90 \mathrm{~s}$, it was established that DDW in the composition of marzipan paste enables a fivefold prolongation of working time with the paste. This is an important factor in manual manufacture of decorative semi-finished products. Adhesive and cohesive strength increases $1.7-2.1$ and 1.6 times, respectively.

3. It was confirmed that the use of glycerin in composition of marzipan DDW in an amount of $5 \%$ of the total weight of dry components is advisable. This measure makes it possible to reduce adhesion-cohesion interaction close to the marzipan pastes prepared by conventional technology. Glycerin softens marzipan pastes and improves its formability. This concentration enables consistency adjustment within the desired range for pasty semi-finished decorative products.

4. According to the results of comprehensive studies, lines of use of marzipan pastes were substantiated based on structural properties:

- TICP marzipan pastes are intended for topping and spreading interlayers in wads and confectionery products where paste spread ability is the main consistency characteristic;

- CFP marzipan pastes are intended for making candies, candy sticks, bars and molding figured products where paste formability is the main consistency characteristic.

Ranges of rational DDW and glycerin concentrations in compositions of marzipan pastes were determined by the method of compromise solutions. Depending on the line of technological use, rational DDW contents of $20 \mathrm{wt} . \%$ and 30 wt. \% were established for TICP and CFP marzipan paste compositions, respectively. Glycerin content was established at a level of $5 \mathrm{wt}$ \%. 


\section{References}

1. Nazarova, O. U., Chuprina, O. A. (2018). Current status of confectionery production as of a segmentof food industry. Ekonomika i suspilstvo, 16, 953-958.

2. Kravchenko, M., Yaroshenko, N. (2017). Study into effect of plant supplements on the quality indicators of gingerbread and similar spice-cakes. Eastern-European Journal of Enterprise Technologies, 5 (11 (89)), 45-54. doi: https://doi.org/10.15587/17294061.2017.110168

3. Tamova, M. Yu., Shchikarev, A. N., Basyuk, A. S. (2015). Trends and innovations of the global confectionery industry. Nauchnye trudy KubGTU, 14, 176-183.

4. Kravchenko, M., Mihailik, V., Yakymchuk, D., Dzyundzya, O., Burak, V., Romanenko, O., Valko, M., Korolenko, E., Osypenkova, I., Bondarchuk, Z. (2019). Research into the structural-mechanical properties of shortbread dough with oilseed meals. Eastern-European Journal of Enterprise Technologies, 3 (11 (99)), 52-59. doi: https://doi.org/10.15587/1729-4061.2019.170617

5. Dorn, G., Savenkova, T., Sidorova, O., Golub, O. (2015). Confectionery goods for healthy diet. Foods and Raw Materials, 3 (1), 70-76. doi: https://doi.org/10.12737/11240

6. Capanoglu, E., Boyacioglu, D. (2008). Improving the quality and shelf life of turkish almond paste. Journal of Food Quality, 31 (4), 429-445. doi: https://doi.org/10.1111/j.1745-4557.2008.00210.x

7. Levchenko, M. A., Tarasenko, N. A. (2015). Pat. No. 2605195 RF. Funktsional'naya konditerskaya smes' dlya izgotovleniya martsipana. No. 2015113849; declareted: 14.04.2015; published: 24.11.2016, Bul. No. 31.

8. Fernandez, M. L., Santos, M. E. S. M. (2018). Effects of consuming sweeteners on metabolic disorders. Journal of Nutrition, Food Research and Technology, 1 (2), 34-38. doi: https://doi.org/10.30881/jnfrt.00008

9. Suez, J., Korem, T., Zeevi, D., Zilberman-Schapira, G., Thaiss, C. A., Maza, O. et. al. (2014). Artificial sweeteners induce glucose intolerance by altering the gut microbiota. Nature, 514 (7521), 181-186. doi: https://doi.org/10.1038/nature13793

10. Baranova, Z. A., Tarasenko, N. A. (2015). Pat. No. 2583087 RF. Konditerskaya smes' dlya izgotovleniya martsipana. No. 2015104611/13; declareted: 11.02.2015; published: 10.05.2016, Bul. No. 13.

11. Pat. No. 2592109 RF. Konditerskaya smes' dlya izgotovleniya persipana (2015). No. 20150141; declareted: 14.04.2015; published: 28.06.2016, Bul. No. 20.

12. Tarasenko, N. A., Novozhenova, A. D. (2015). Pat. No. 2583090 RF. Sposob proizvodstva martsipanovyh plitok funktsional'nogo naznacheniya. No. 20150211; declareted: 11.02.2015; published: 11.05.2016, Bul. No. 13.

13. Maksimenko, D. N., Krasin, P. S., Tarasenko, N. A. (2016). Pat. No. 2632334 RF. Sposob proizvodstva martsipanovyh izdeliy. No. 2016127117; declareted: 05.07.2016; published: 04.10.2017, Bul. No. 28.

14. Gondar, O., Romanchuk, I. (2015). Changing of mineral composition dry demineralized whey at different processing methods. Zbirnyk naukovykh prats Vinnytskoho natsionalnoho ahrarnoho universytetu, 1 (1 (89)), 94-99.

15. Gnezdilova, A., Burmagina, T., Kurenkova, L. (2015). Investigation of rheological characteristics of concentrated milk products with a complex carbohydrate and protein composition. Foods and Raw Materials, 3 (2), 60-64. doi: https://doi.org/10.12737/13119

16. Hramtsov, A. (2015). Glycoomics clusters of lactose and its derivatives in nanotechnology of living cultures. Foods and Raw Materials, 3 (1), 3-12. doi: https://doi.org/10.12737/11168

17. Gnytsevych, V., Yudina, T., Deinychenko, L., Nykyforov, R., Nazarenko, I. (2018). Survey of characteristics of dairy-protein concentrates in the low-temperature storage process. Eastern-European Journal of Enterprise Technologies, 1 (11 (91)), 16-21. doi: https://doi.org/10.15587/1729-4061.2018.120749

18. Kozlova, O. (2014). A Study of Properties of Structure-Stabilizing Agents for Products Based on Dairy Raw Materials. Foods and Raw Materials, 2 (2), 16-25. doi: https://doi.org/10.12737/5455

19. Yudina, T., Nazarenko, I., Nykyforov, R. (2015). Research on the quality of milk and vegetable mince based on the concentrate of buttermilk. Eastern-European Journal of Enterprise Technologies, 3 (10 (75)), 10-14. doi: https://doi.org/10.15587/17294061.2015.43407

20. Kravchenko, M., Rybchuk, L. (2019). Optimization of the chemical composition of marzipan past. Proceedings of the Tavria State Agrotechnological University, 3 (19), 233-240. doi: https://doi.org/10.31388/2078-0877-19-3-233-240

21. Pat. No. 2370087 RF. Sposob prigotovleniya konditerskoy pasty (2008). No. 2008121837; declareted: 27.05.2008; published: 20.10.2009, Bul. No. 29 .

22. Kokhan, O. O., Salikh, N. S. (2017). Pat. No. 121755 UA. Tsukrova mastyka. No. 201707206; declareted: 10.07.2017; published: 11.12.2017, Bul. No. 23.

23. Kravchenko, M., Rybchuk, L. (2019). Kondyterski mastyky z hlitserynom: reolohichni kharakterystyky. Tovary i rynky, 2, 87-97. Available at: http://tr.knteu.kiev.ua/files/2019/02(30)2019/10.pdf

24. Horalchuk, A. B., Pyvovarov, P. P., Hrynchenko, O. O., Pohozhykh, M. I., Polevych, V. V., Hurskyi, P. V. (2006). Reolohichni metody doslidzhennia syrovyny i kharchovykh produktiv ta avtomatyzatsiia rozrakhunkiv reolohichnykh kharakterystyk. Kharkiv: KhDUKhT, 63. 